\title{
Evaluation of Learning and Teaching Practice for Design-oriented Engineering Modules
}

\author{
Min Chen ${ }^{1, a}$, Shunqi Zhang ${ }^{2, b,{ }^{*}}$, Martijn Tenbhomer ${ }^{1, c}$ and Derrick Tate ${ }^{1, d}$ \\ ${ }^{1}$ Department of Industrial Design, Xi'an Jiaotong - Liverpool University, \\ Suzhou, P.R. China \\ ${ }^{2}$ School of Mechatronic Engineering and Automation, Shanghai University, \\ Shanghai, P.R. China \\ amin.chen@xitlu.edu.cn, ${ }^{\mathrm{b}}$ zhangsa@shu.edu.cn , \\ c martijn.Tenbhomer@xitlu.edu.cn, ${ }^{d}$ d.tate@xitlu.edu.cn
}

Keywords: Design-oriented mechanics module, Evaluation models, Transdisciplinary interaction

\begin{abstract}
Learning and teaching of engineering modules to design-oriented students is always a very challenging task for a transdisciplinary programme. In this paper, different evaluation models and approaches of teaching were discussed and extended. In particular, mechanics module "Statics and Solids" was taken as the application example to demonstrate the significance of evaluation. Students' evaluation questionnaire and colleagues' peer review are mainly analyzed for the further step of action. Reflections and positive changes were did based on the analysis of the former experience. Finally further reflection on modules connection and research-led learning and teaching were discussed.
\end{abstract}

\section{Introduction}

Engineering modules, like Statics, Mechanics of Material, Fluid Mechanics and Thermodynamics are integrated with advanced mechanics and mathematics knowledge. It tended to be accepted easily for engineering students, while frequently challenged by industrial design (IND) students for their difficulty, abstraction and usefulness. Moreover, the change keeps continually, like class size, teaching tools, as well as the nature of students.

How to provide a high quality engineering module, meanwhile how to enhance design students' experience of learning and teaching are always specific key questions pondered by module leader. There are many available models and approaches of teaching and learning in pedagogics for our reference. This paper will address the comprehension and application of the evaluation model of learning and teaching in design-oriented engineering module.

\section{Evaluation models}

There are many evaluation models in higher education. In this paper, three influential models are discussed and compared for the further application on author's own reflection case.

\section{- Kolb's experiential learning model (1984)}

Kolb's learning cycle consists of four stages, as shown in Figure 1 (a).

(1) Concreate experience (having new experience)

(2) Reflective observation (reflecting on experience)

(3) Abstract conceptualization (concluding from the experience)

(4) Active experimentation (testing your learnt experience) 


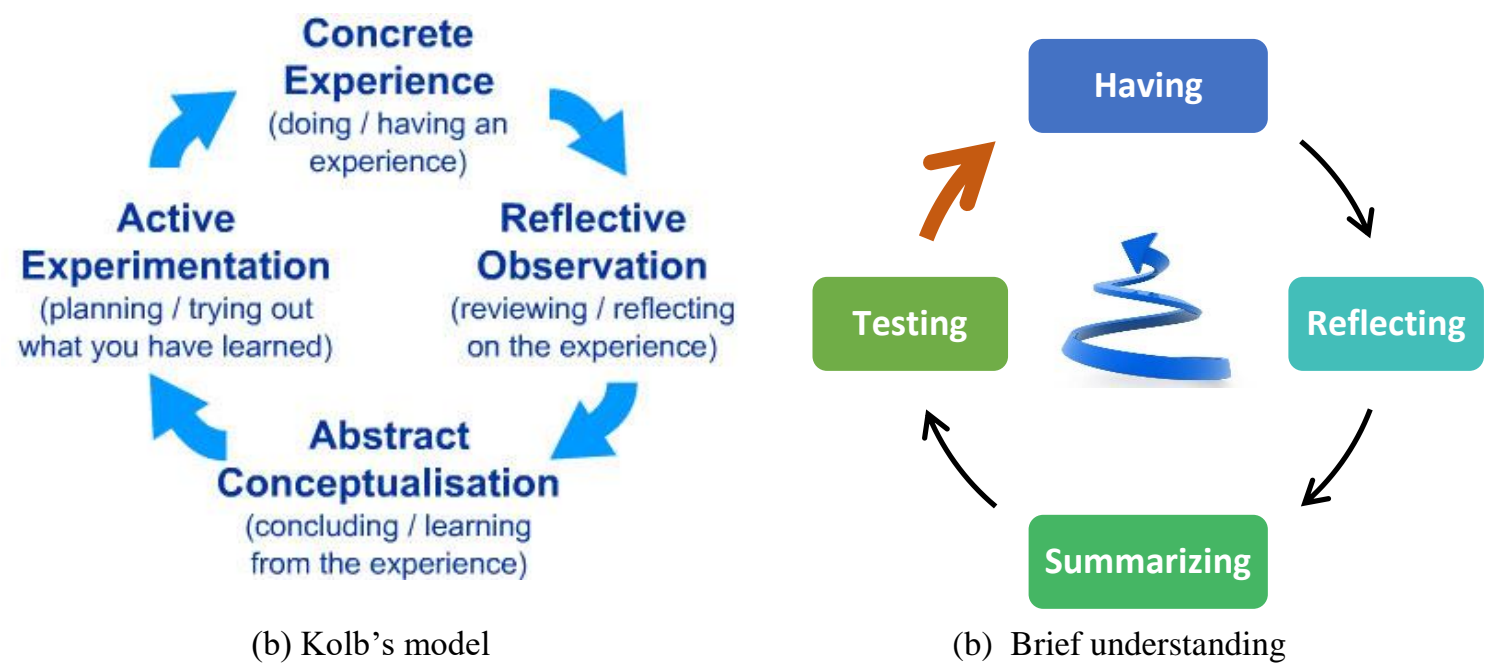

Figure 1. Kolb's experiential learning cycle (Kolb 1981, Kolb 1984)

Kolb's model described the experiential learning process, in more precise description, a spirally increasing way, as shown in Figure 1 (b).

\section{- Gibbs reflective cycle model (1988)}

Graham Gibbs also described a cycle model for the reflective process in more detailed way. There are six stages in Gibbs's model, as shown in Figure 2. From these series of interactive questions, faculty of higher education are encouraged to think and analyze their activities or experience systematically.

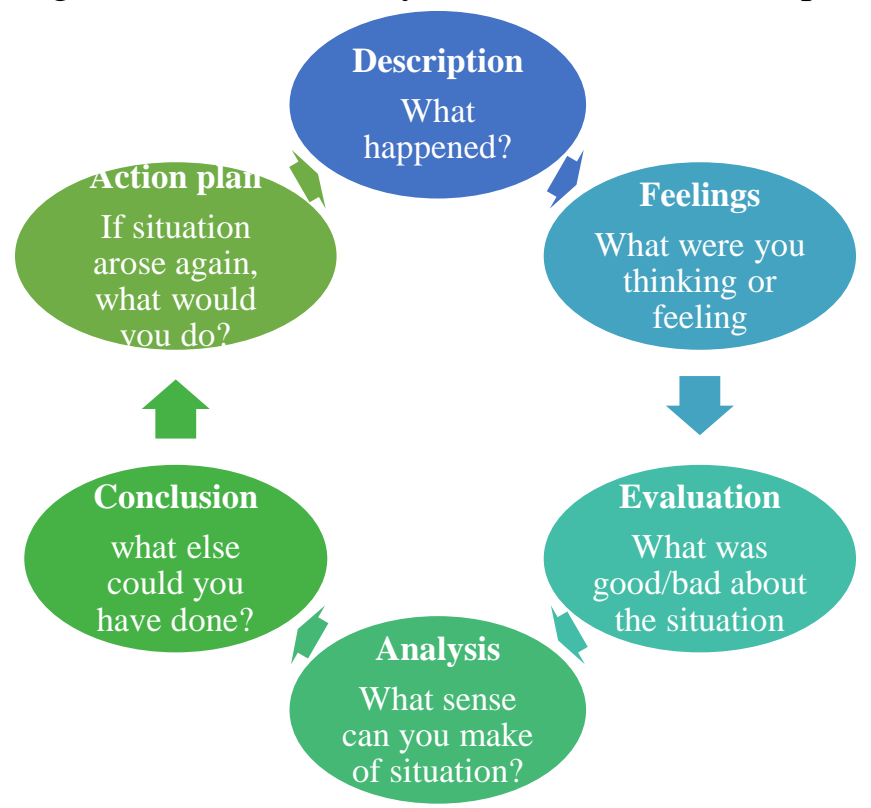

Figure 2. Gibbs' reflective cycle (Gibbs 1988, Dye 2011)

\section{- Brookfield's four lenses model (1995)}

In Brookfield's book, "Becoming a Critically Reflective Teacher"(Brookfield 1995), he takes a deep insight on how faculty in higher education may develop themselves from critical refection. In the latest revised $2^{\text {nd }}$ edition in 2017(Brookfield 2017), new features haven been expanded, for instance, due to the internet technology development, today's classroom formats vary a lot, like online course, which makes the education possible even the teacher and student are in different space and time. In summary, 
Brookfield proposes four lens for teachers in the critical reflection process and the correlation of these lenses in progress, as shown in Figure 3 .

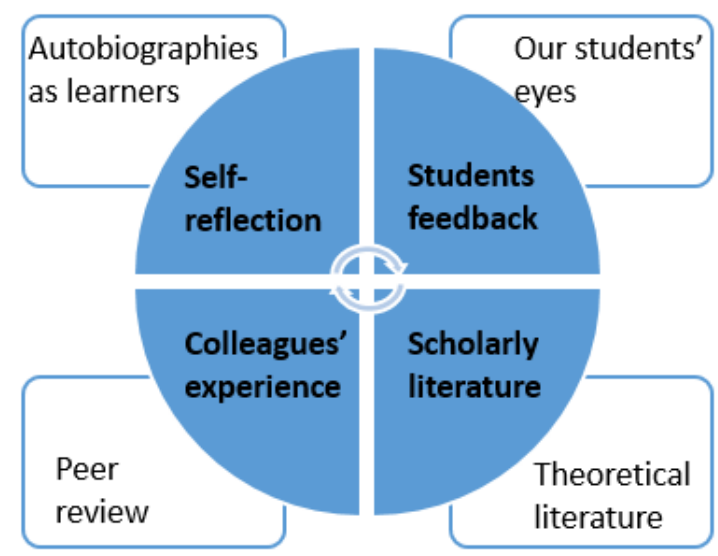

Figure 3. Brookfield's four lenses model(Brookfield 1995, Brookfield 2017)

"Reflection" is key concept in Brookfiled's four lenses model, which present the approaches and angles of critical reflection. This similar philosophy was proposed by Zengzi (505-435 BC), a very influential Chinse philosopher and disciple of Confucius. Zenzi said: "Each day I reflect myself in three ways: in doing things for others, have I been disloyal? In my interactions with friends, have I been untrustworthy? Have not practiced what I have preached?" As professional university teachers, we may reflect from various perspectives.

Kolb's cycle was published before Gibb's cycle. Both focuses on the reflecting process, while Kolb's cycle was too narrow and undeveloped (Heron 1992). Gibb's cycle present more concreate steps. Brookfield's model highlighted the approaches of reflection. In author's evaluation process, Gribb's model and Brookfield's model are used as the reference.

\section{Case study: Learning and teaching of engineering modules}

In this paper, the mechanics modules for IND Y2 students are adopted as the illustrative case. The reflection of teaching is based on the combined application of Gibb's model and Brookfield's model. Firstly the refection process in Gibb's cycle model was clearly understood. Based on the Description (stage 1) and Feelings (Stage 2), the Evaluation (Stage 3) and Analysis (Stage 4) are made based on the lenses suggested by Brookfield. Finally, Conclusion (Stage 5) and Action Plan (Stage 6) were implemented for a positive enhancement.

\subsection{Mechanics module}

Those mechanics modules are level 1 (Year 2) modules delivered to undergraduate students of Industrial Design. The key challenges of teaching for design background students were summarized in the following aspects:

- Abstract contents. It is a common feature that mechanics describe the physical phenomena in mathematical models, which are integrated much deduction procedures. Moreover, it contains many English terminologies, which is a troublesome issue for local Chinese students.

- Diverse background and interest of IND students. IND students are recruited from both Science and Art background in their high school, unlike pure science background for engineering departments. The students who have Art background are normally lack of fundamental physics knowledge and have no interest in engineering related modules.

- Different Appeal for future career. IND students are expected to be future designer, instead of engineer, furthermore, if go to more detailed career directions, parts of students are for graphic design, 
service design, which are normally regarded as no relations to engineering technique. However, part of students will further their master study or career in engineering-related product design, which have high requirement in technique knowledge.

\subsection{Evaluation sources}

In general, the evaluation sources mainly consisted of three parts:

- Students: feedback, module evaluation questionnaires, staff student liaison committee, student experience committee

- Self: peers, external examiners/moderators, annual program review and internal programme review

- External sources: employers (Industry), professional bodies, league tables

In this section, author will discuss two of these sources thoroughly, module questionnaire and peer review, which have big impact on author's reflection.

\section{- Module Evaluation Questionnaire}

The students' module questionnaire mainly consists three parts: Student information, Module questions and Teacher questions.

From "Student information", the learning hours spent on the module outside class were collected. This is very important to evaluate an appropriate working load for students(Moore 2003). From "Module questions", feedback about module objectives, learning outcomes, readings, supporting activities and assessments were collected. If over $10 \%$ of total students have no satisfaction of learning experience, the module leader should reconsider the teaching approach seriously. From "Teacher questions", feedback about teacher's working attitude, preparation, knowledge, etc. were collected. These data may reflect not only the professional teaching skills but also the personal attitude.

\section{- Peer review}

Peer review is proved to be a very supportive way to enhance teaching quality(Race, Chapman 2013). The author was reviewed by the colleagues two times. According to their observation, there are mainly tow strengths in the teaching:

(a) good use of multimedia materials (video, images) to explain technique applications

(b) good interaction with students to stimulate their interest and enhance their learning efficiency

Two constructive suggestions were given by the observers:

(a) not well-considered lecture planning and organization, for instance, small font size for students who are sitting back of the large classroom, no break between two lecture hours and noise from projectors.

(b) fast delivery pace, especially for a lecture with many professional terminologies and mathematics model.

Some changes were done according to the suggestions of reviewer, like well preparation of the facility and lecture-tutorial mixed teaching rhythmus to help students catch up the contents and enhance the efficiency (Anderson, Krathwohl 2001).

\section{Action and improvement: interaction among transdisciplinary modules}

The reflection was performed in Brookfield's four lenses: self as a learners, students' eyes, colleagues' experience and theoretical literatures. Further step is to take action for the improvement. The major change here is to enhance the interaction among transdisciplinary modules in order to stimulate design students' motivation of learning mechanics module and to train their transferrable skills.

Table 1 shows the development process of the coursework designation. 
Table 1. Development of coursework (CW) designation

\begin{tabular}{|c|c|c|c|}
\hline & $2015 / 16$ S1 & 2016/17 S1 & $2017 / 18$ S1 \\
\hline Brief task & $\begin{array}{l}\text { Theoretical mechanics } \\
\text { analysis and discussion } \\
\text { of given structure }\end{array}$ & $\begin{array}{l}\text { Use structural components to } \\
\text { design a chair and analyze its } \\
\text { simplified theoretical } \\
\text { mechanics model }\end{array}$ & $\begin{array}{l}\text { Use structural components } \\
\text { to design, modeling and } \\
\text { analysis of a bookshelf in } \\
\text { Creo Parametric \& Simulate }\end{array}$ \\
\hline Deliver & $\begin{array}{l}\text { Explained in lecture } \\
\text { time }\end{array}$ & $\begin{array}{l}\text { Additional joint workshop was } \\
\text { organized for chair design } \\
\text { history and demonstration of } \\
\text { numerical analysis in ANSYS }\end{array}$ & $\begin{array}{l}\text { Additional workshop was } \\
\text { organized for Creo modeling } \\
\text { and analysis. } \\
\text { This CW was interacted } \\
\text { with IND112 Computer aid } \\
\text { design and modelling (3D) }\end{array}$ \\
\hline Assessment & $\begin{array}{l}\text { Group work } \\
\text { (set up group by } \\
\text { themselves) }\end{array}$ & $\begin{array}{l}\text { Group work } \\
\text { (set up group by themselves) }\end{array}$ & $\begin{array}{l}\text { Group work } \\
\text { (group assigned based on } \\
\text { alphabetical order) }\end{array}$ \\
\hline Submission & Report (15\%) & $\begin{array}{l}\text { A3 portfolio }(10 \%)+\text { report } \\
(5 \%)\end{array}$ & $\begin{array}{l}\text { A3 poster }(10 \%)+\text { report } \\
(5 \%)\end{array}$ \\
\hline Intension & Application case & $\begin{array}{l}\text { Connection between } \\
\text { Mechanics and Design }\end{array}$ & $\begin{array}{l}\text { Connection between } \\
\text { Mechanics and Design } \\
\text { Reach-led case study }\end{array}$ \\
\hline
\end{tabular}

In 2015/16, the CW stayed inside the individual module. In 2016/17, the CW integrated design and statics. It was an attempt for the connection between engineering and design. In 2017/18, the CW was devised more clearly with the consideration of programme learning outcomes. And this change also encouraged the students find their practical solution in their design work through numerical solution. It is also an attempt for the research-led study case in order to meet the increasing demand of digital design in industry.

\section{Discussion and conclusion}

This paper discussed the evaluation models and their applications in design-oriented engineering modules teaching. The Gibb's model and Brookfield model were simultaneously referred in mechanics modules. Students' evaluation questionnaire and peer review are mainly discussed for the further step of action. Reflections and changes were did based on the analysis of the former experience. Furthermore, to be an excellent professional teacher, the deliberate and sustained research for approaches to enhance the teaching should be constantly engaged. How to enhance the connection between engineering modules and other modules, like design and culture, and how to involve more research study in the module are two main issues to be further pondered and reflected by the module leader.

\section{Acknowledgements}

This work was carried out with the support from the Jiangsu Science and Technology Programme (Grant No. BK20170418) and the University Natural Science Research Programme of Jiangsu Province (Grant No. 16KJB460021).

\section{Reference}

[1] Kolb, D., Learning styles and disciplinary differences. The modern American college, 1981: p. 232-255.

[2] Kolb, D., Experiential learning: Experience as the source of learning and development ed. E. Cliffs. 1984: NJ: Prentice-Hall. 
[3] Gibbs, G., Learning by Doing: A guide to teaching and learning methods, in Further Education Unit. 1988, Oxford Polytechnic: Oxford.

[4] Dye, V., Reflection, Reflection, Reflection. I'm thinking all the time, why do I need a theory or model of reflection, in Developing Reflective Practice: A guide for beginning teachers., D. McGregor and L. Cartwright, Editors. 2011, Maidenhead: McGraw-Hill Education. p. 217-234.

[5] Brookfield, S.D., Becoming a Critically Reflective Teacher: 1st edition. 1995: Jossey-Bass.

[6] Brookfield, S.D., Becoming a Critically Reflective Teacher: 2nd revised edition. 2017: Jossey Bass.

[7] Heron, J., Feelings and Personhood: Psychology in Another Key. 1992: SAGE Publications.

[8] Moore, I., Evaluatiing a Materials Course. 2003, The UK Centre for Materials Education.

[9] Race, P., Chapman, F., Cooke, B., et al., Using peer observation to enhance teaching. 2013: Leeds Met Press.

[10] Anderson, L.W., Krathwohl, D.R., Airasian, P.W., et al., A Taxonomy for Learning, Teaching, and Assessing: A revision of Bloom's Taxonomy of Educational Objectives. 2001: New York: Pearson, Allyn \& Bacon. 